\title{
Responses of different cell lines from ocular tissues to elevated hydrostatic pressure
}

\author{
Martin B Wax, Gülgün Tezel, Shigeki Kobayashi, M Rosario Hernandez
}

\begin{abstract}
Backgroundlaims-Mechanical forces are thought to induce cellular responses through activation of signalling pathways. Cells within the intraocular environment are exposed to constant changes in the levels of intraocular pressure. In this study, an attempt was made to determine the acute effects of elevated hydrostatic pressure on different intraocular cells grown in culture.
\end{abstract}

Methods-Different cell lines derived from ocular tissues including nonpigmented and pigmented ciliary epithelium, trabecular meshwork, retina, and lamina cribrosa were incubated in a pressurised chamber at $50 \mathrm{~mm} \mathrm{Hg}$ in a culture incubator at $37^{\circ} \mathrm{C}$ for up to 6 hours. Control cells were incubated at atmospheric pressure. The viability of the cells was examined using their intracellular esterase activity. The morphology and cytoskeleton of the cells were investigated using microscopy and phalloidin staining. Adenylyl cyclase activity was assessed by measuring the conversion of $\left[{ }^{3} \mathrm{H}\right]-\mathrm{cAMP}$ from $\left[{ }^{3} \mathbf{H}\right]$-ATP in response to elevated hydrostatic pressure for 1-6 hours. In addition, at the end of incubation period under elevated hydrostatic pressure the recovery of adenylyl cyclase activity to control levels was examined.

Results-Cell viability did not change following exposure to elevated hydrostatic pressure for 6 hours. Cells subjected to elevated hydrostatic pressure demonstrated morphological differences characterised by a more rounded shape and a redistribution of actin stress fibres that was most prominent in lamina cribrosa astrocytes. A time dependent increase in basal adenylyl cyclase activity, and a decrease in maximum forskolin stimulated activity were observed in all cell lines following exposure to elevated hydrostatic pressure.

Conclusion-These observations demonstrate that cell lines from different ocular tissues are sensitive to changes in external pressure in vitro. They exhibit morphological and cytoskeletal changes as well as significant alterations of intracellular adenylyl cyclase activity following exposure to acute and sustained levels of elevated hydrostatic pressure of up to 6 hours' duration.

(Br f Ophthalmol 2000;84:423-428)
In vivo, most living cells are exposed to a variety of biomechanical forces by virtue of their relation with the microenvironment. Intracellular mediator pathways by which cells respond to biomechanical deformation are widely explored in biology. It has been shown that increased production of cAMP, prostaglandin $\mathrm{E}_{2}$, or prostacyclin may mediate the effects of compressive pressure on cells in culture. ${ }^{1-3}$ Studies of different cells from the human body reveal the effects of elevated hydrostatic pressure on cell shape and function. For example, in endothelial cells exposed to elevated hydrostatic pressure, release of bFGF can be induced independently of cell injury or death and may account for subsequent morphological and proliferative responses. ${ }^{4}$ Similarly, elevated hydrostatic pressure is an important stimulator of matrix synthesis in cartilage. This results in the increased expression of cytokines and heat shock proteins thought to be necessary for the repair of damaged or disorganised cytoskeleton. ${ }^{5}$ Regarding ocular tissues, it has been shown that human lamina cribrosa cells may react to pressure changes in their environment by modulating the production and secretion of extracellular matrix macromolecules such as seen for collagen type $\mathrm{I}^{6}{ }^{6}$

Elevated intraocular pressure has been proposed to be an important risk factor for the development of glaucomatous optic neuropathy ${ }^{78}$ and many ocular cells are exposed to constant variations of intraocular pressure, which generate mechanical forces affecting cell behaviour. However, individual cellular responses of ocular tissues to elevated pressure or to pressure related stress remain largely unstudied. In this study, we investigated the responses of different ocular cells to elevated hydrostatic pressure by examining the cell viability and morphology. We also studied whether cells derived from ocular tissues demonstrate biochemical alterations of basic intracellular enzyme pathways such as adenylyl cyclase following exposure to sustained elevation of hydrostatic pressure for several hours.

Table 1 Viability of the cells

\begin{tabular}{|c|c|c|}
\hline & \multicolumn{2}{|c|}{ Cell viability (\%) (mean (SD)) } \\
\hline & Without pressure & With pressure \\
\hline NPE & $97.21(0.4)$ & $97.76(0.6)$ \\
\hline $\mathrm{PE}$ & $97.86(0.4)$ & $97.16(1.6)$ \\
\hline $\mathrm{TM}$ & $97.40(0.9)$ & $97.43(1.0)$ \\
\hline Astrocytes & $97.88(0.3)$ & $97.36(0.4)$ \\
\hline Retina cells & $94.67(2.7)$ & $94.00(1.9)$ \\
\hline
\end{tabular}

$\mathrm{NPE}=$ non-pigmented ciliary epithelium $; \mathrm{PE}=$ pigmented ciliary epithelium, TM = trabecular meshwork cells; Astrocytes = lamina cribrosa astrocytes.
Accepted for publication 6 December 1999 

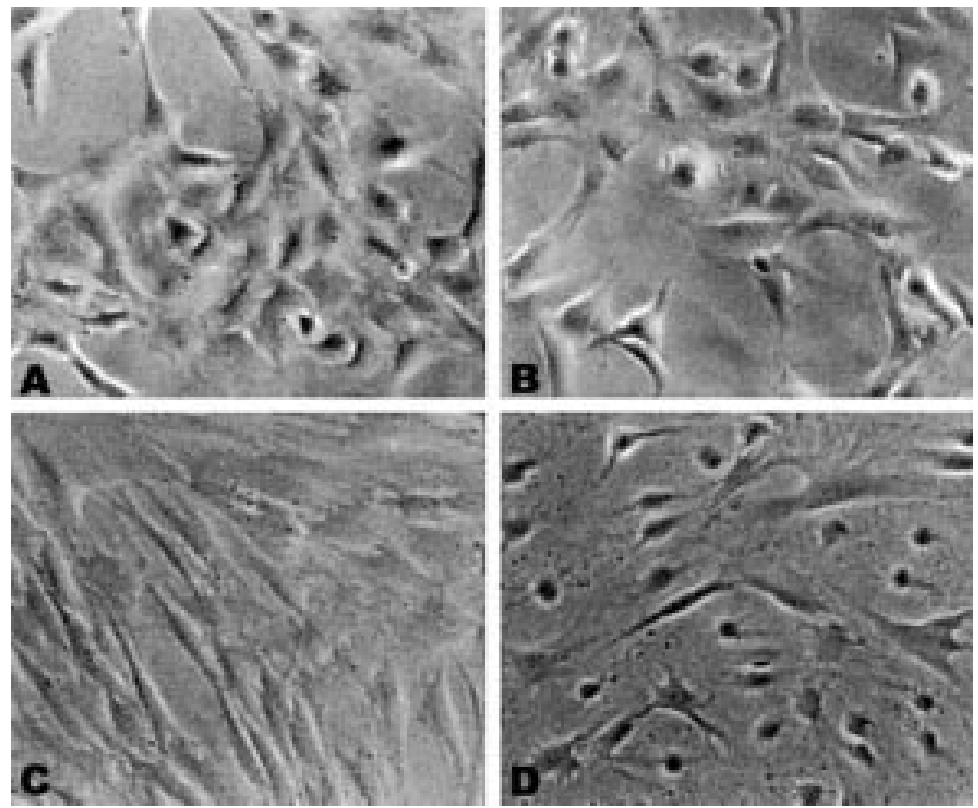

Figure 1 Morphological changes of cells exposed to sustained elevated hydrostatic pressure. Phase contrast micrographs of living trabecular meshwork cells $(A, B)$ and lamina cribrosa astrocytes $(C, D)$. Note in $(B)$ and $(D)$ that cells exposed to elevated hydrostatic pressure to $50 \mathrm{~mm} \mathrm{Hg}$ for 6 hours adopt a rounder shape when compared with control cells shown in $(A)$ and $(C)$ (original magnification $\times 20$ ).

We present evidence that acute and sustained elevated hydrostatic pressure can affect cell morphology as well as alter adenylyl cyclase activity in cell lines derived from several intraocular tissues including the ciliary epithelium, trabecular meshwork, retina, and lamina cribrosa.
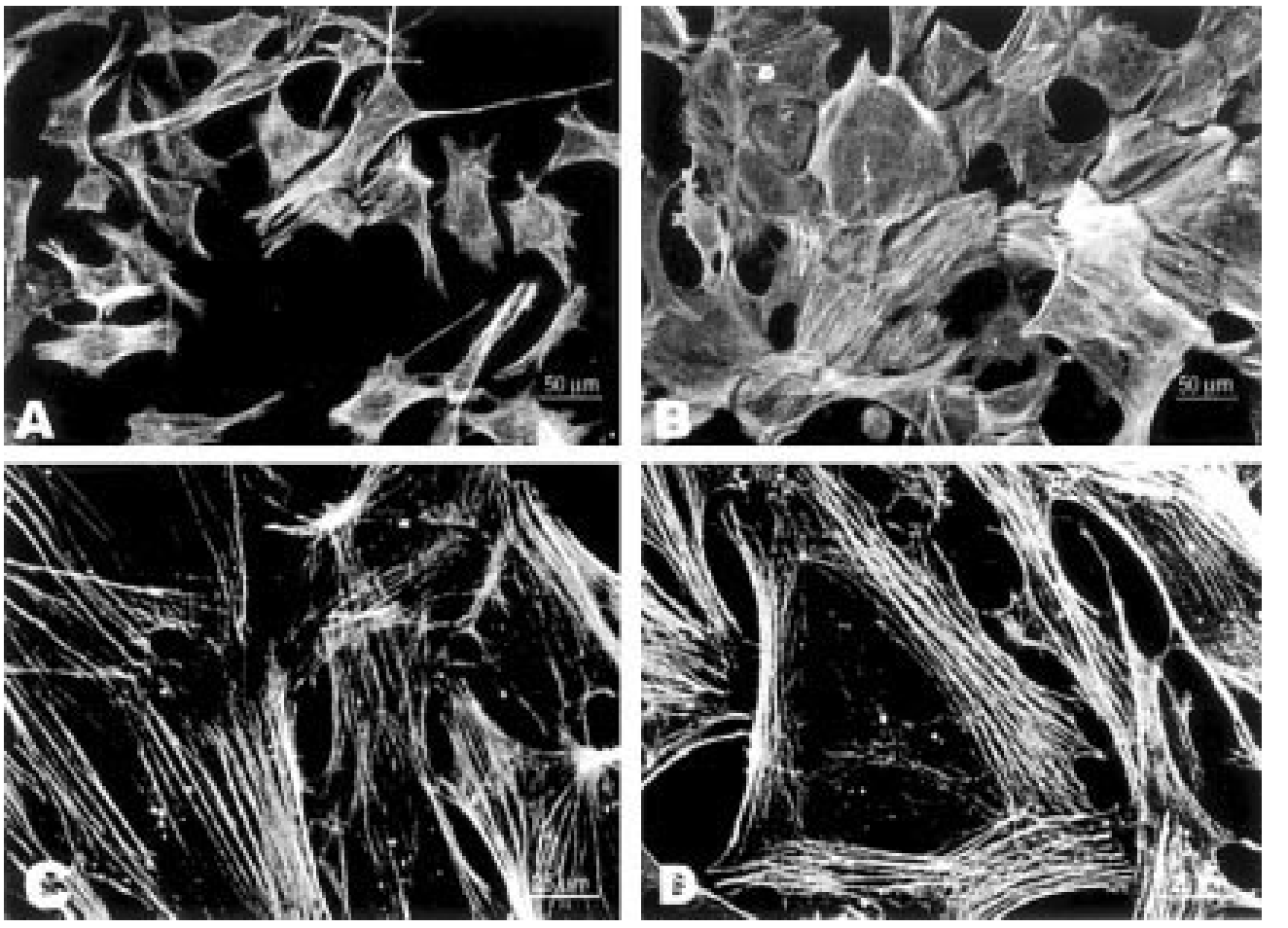

Figure 2 Effects of elevated hydrostatic pressure on F-actin cytoskeleton. (A) Human trabecular meshwork cells incubated at atmospheric pressure. (B) Human trabecular meshwork cells exposed to elevated hydrostatic pressure. Although control cells shown in (A) exhibit short processes and a diffuse filamentous staining, cells exposed to elevated hydrostatic pressure shown in (B) exhibited redistribution of actin fibres and retraction of processes. (C) Lamina cribrosa astrocytes incubated at atmospheric pressure. (D) Lamina cribrosa astrocytes incubated at elevated hydrostatic pressure for 6 hours. Note in (D) the displacement of phalloidin stained actin stress fibres to the periphery of the cell. Control cells shown in (C) are elongated and actin stress fibres are distributed throughout the cytoplasm.

\section{Methods}

CELL CULTURES

eigmented ciliary epithelial cells used in our experiments were clones derived from human (non-pigmented) or simian virus 40 (SV-40) as previously described. $^{9-11}$ Transformed human trabecular meshwork cells were provided as a gift by Dr L DeSantis (Alcon Laboratories, Fort Worth, TX, USA). ${ }^{12}$ Ciliary epithelial and trabecular cells were grown in Dulbecco's modified Eagle's medium (DMEM) with 5\% fetal calf serum and 5\% each of penicillin and streptomycin. An immortalised rat retinal cell line (E1A.NR3) was provided by Dr G M Seigel which contains cells expressing antigens specific for photoreceptors, bipolar cells, ganglion cells, and retinal glial cells was used. ${ }^{13}$ These cells were maintained in DMEM supplemented with $10 \%$ fetal bovine serum and $1 \%$ each of non-essential amino acids, L-glutamine, vitamins, and antibiotics. Third to fourth passages of human lamina cribrosa astrocytes were cultured in DMEM/F-12 supplemented with $10 \%$ fetal bovine serum, 5 $\mathrm{ng} / \mathrm{ml}$ of human basic pituitary fibroblast growth factor (Biomedical Technologies, Stoughton, MA, USA), $5 \mathrm{ng} / \mathrm{ml}$ of human platelet derived growth factor-A chain (Sigma, St Louis, MO, USA), and PSFM (10 $000 \mathrm{U} / \mathrm{ml}$ penicillin, $10000 \mu \mathrm{g} / \mathrm{ml}$ streptomycin, and 25 $\mu \mathrm{g} / \mathrm{ml}$ amphotericin B) as previously described. ${ }^{14}$ All tissue culture reagents were purchased from Gibco (Gaithesburg, MD, USA).

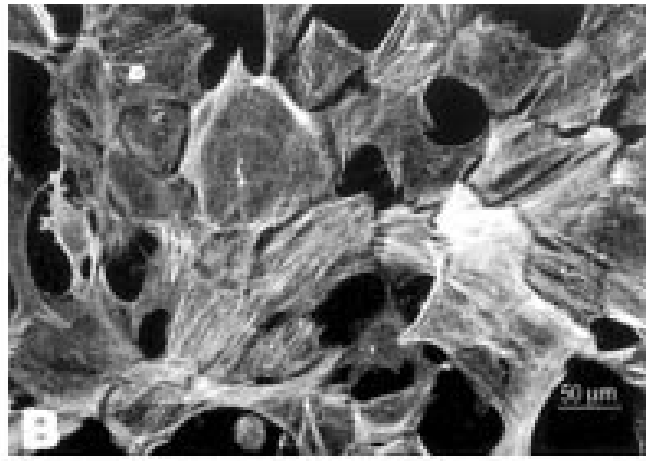




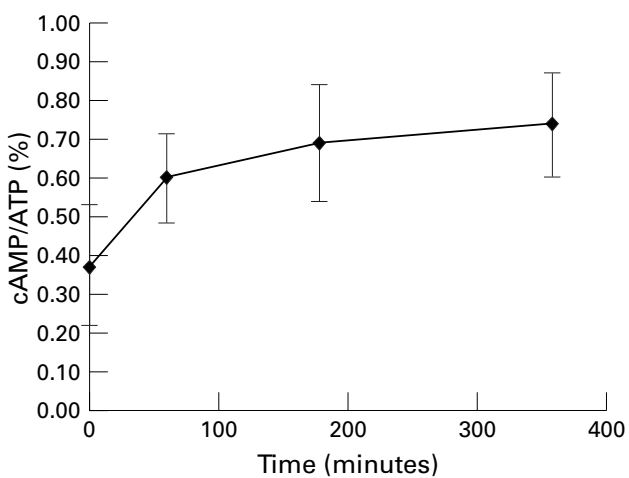

Figure 3 Time course of changes seen in the basal adenylyl cyclase activity of lamina cribrosa astrocytes exposed to elevated hydrostatic pressure up to 6 hours.

\section{STUDY DESIGN}

Cells plated in six well plates (Costar, Cambridge, MA, USA) at a density of 3-10 $\times 10^{4}$ cells/well and grown to semiconfluence in $2-7$ days were incubated with serum free medium overnight. A closed pressurised chamber (92\% air, $8 \%$ carbon dioxide) equipped with a manometer, that can be placed in a tissue culture incubator, was used so that the cells in six well plates could be exposed to elevated hydrostatic pressure. ${ }^{6}$ Cells were placed in the chamber and the pressure was elevated to 50 $\mathrm{mm} \mathrm{Hg}$. The chamber was subsequently placed in a tissue culture incubator at $37^{\circ} \mathrm{C}$. To examine the time course of cellular responses, the elevated pressure was maintained for 1,3 , or 6 hours. Control cells from identical passage of cell lines were simultaneously incubated in a tissue culture incubator at atmospheric pressure at $37^{\circ} \mathrm{C}$. At the end of the incubation period, the cells were immediately subjected to experiments described below. In addition, some of the plates incubated under elevated hydrostatic pressure were transferred to normal atmospheric pressure condition for 3 or 24 hours in order to examine the recovery of cell responses.

We examined the viability and morphology of the cells incubated in the presence or absence of elevated hydrostatic pressure. Furthermore, we assayed basal and forskolin stimulated adenylyl cyclase activity in addition to somatostatin attenuation of forskolin stimu-

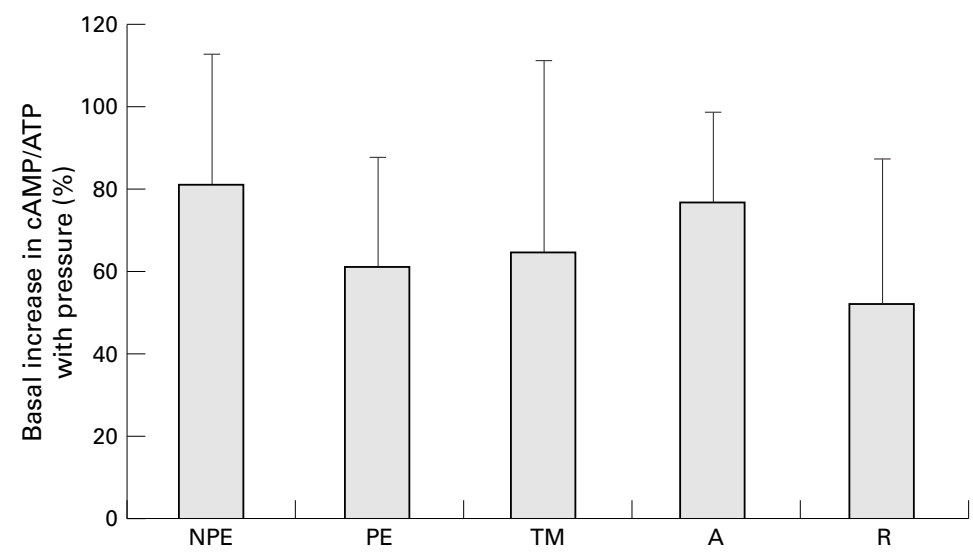

Figure 4 Percentage of increased basal adenylyl cyclase activity in different cells from ocular tissues with elevated hydrostatic pressure. NPE = non-pigmented ciliary epithelium; $P E=$ pigmented ciliary epithelium; $T M=$ trabecular meshwork cells; $A=$ lamina cribrosa astrocytes; $R=$ retina cells. lation in order to assess the effects of hydrostatic pressure on the activity of this signal transduction pathway. The viability of the cells were determined with the Live/Dead Kit (Molecular Probes, Eugene, OR, USA) which contains calcein and ethidium homodimer. ${ }^{15}$ It relies on the intracellular esterase activity within living cells to cleave calcein to form a green fluorescent membrane impermeable product. In dead cells ethidium can easily pass through the compromised plasma and nuclear membranes and attach to the DNA yielding red fluorescence. At least 750 cells were counted under $200 \times$ magnification in three randomly chosen areas using a fluorescence microscope equipped with fluorescein and rhodamine filters (Olympus, Tokyo, Japan). The number of cells was counted using a Coulter counter (Coulter, Hialeah, FL, USA) after trypsinisation of the cells. The viability of the cells was expressed as the average ratio of esterase $(+)$ cells to the total number of cells counted, multiplied by 100 .

In addition to phase contrast microscopy to examine cell shape in response to elevated hydrostatic pressure, we performed F-actin staining using phalloidin to assess the status of actin cytoskeleton. At the end of the incubation period in the presence or absence of elevated hydrostatic pressure, cells grown on coverslips were immediately fixed in acetone at $-20^{\circ} \mathrm{C}$ for 20 minutes, blocked using $5 \%$ horse serum for 30 minutes, and washed in phosphate buffered solution (PBS) containing 1\% bovine serum albumin. The coverslips were then incubated with $50 \mu \mathrm{l}$ of Oregon Green 48-phalloidin (Molecular Probes) for 30 minutes. After washing with PBS, the coverslips were mounted in ProLong Antifade medium. Pressurised and control cells stained with phalloidin were observed and photographed with a Zeiss LSM 410 laser confocal microscope.

\section{ADENYLYL CYCLASE ACTIVITY ASSAY}

After the incubation in the presence or absence of elevated hydrostatic pressure for up to 6 hours, cells were washed three times with PBS. After aspiration of PBS, $1.75 \mathrm{ml}$ of a solution containing $1 \mu \mathrm{Ci}$ adenine $\left[2,8-{ }^{3} \mathrm{H}\right]$ (Dupont, Boston, MA, USA) per well prepared in DMEM, $2 \mathrm{mM}$ HEPES, and $50 \mu \mathrm{l}$ of $10 \mathrm{mM}$ 3-isobutylmethylxanthine (IBMX) (Sigma) were added to each well. During this treatment period cells were incubated at $37^{\circ} \mathrm{C}$ with or without elevated hydrostatic pressure application for 20 minutes. At the end of the pre-incubation period for ${ }^{3} \mathrm{H}$-adenine labelling, cells were treated with DMEM, $100 \mu \mathrm{M}$ forskolin (Calbiochem, La Jolla, CA, USA) solution, or $100 \mu \mathrm{M}$ forskolin plus $2 \mu \mathrm{M}$ somatostatin (Calbiochem) for 20 minutes at $37^{\circ} \mathrm{C}$ with or without elevated hydrostatic pressure application. At the end of the 20 minutes of drug incubation period, $4 \%$ ice cold trichloroacetic acid was added to each well to terminate the reaction. After incubation on ice for 30 minutes, the supernatant was collected from each well, spun for 3 minutes in a Beckman microfuge, and used to assay the conversion of $\left[{ }^{3} \mathrm{H}\right]$-cAMP from $\left[{ }^{3} \mathrm{H}\right]$-ATP following chroma- 

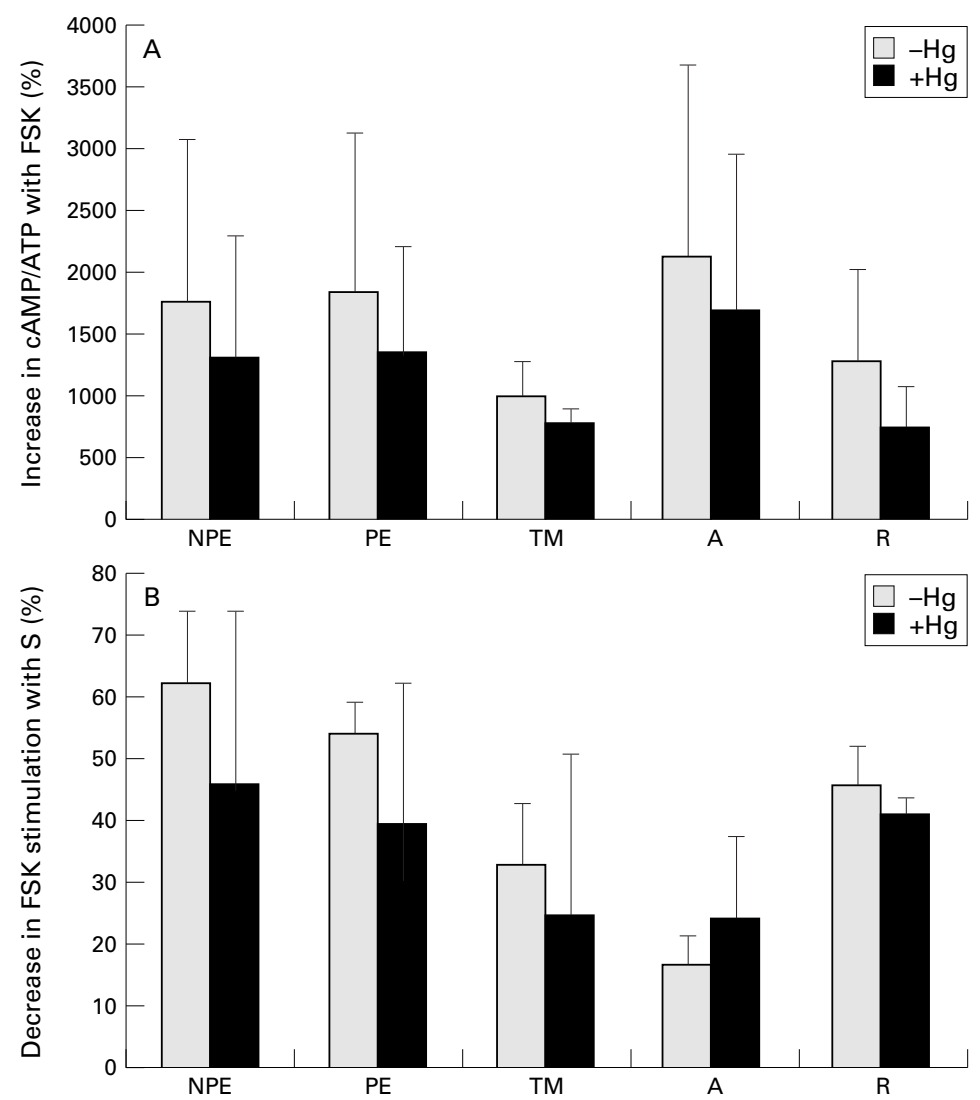

Figure 5 Percentage of stimulated adenylyl cyclase activity in different ocular cells exposed to elevated hydrostatic pressure. (A) Stimulation of adenylyl cyclase activity by forskolin (FSK). (B) Inhibition of forskolin stimulation by somatostatin (S). NPE = non-pigmented ciliary epithelium; $P E=$ pigmented ciliary epithelium; TM = trabecular meshwork cells; $A$ = lamina cribrosa astrocytes; $R=$ retina cells.

tography over Dowex ion exchange resin (BioRad, Richmond, CA, USA) columns as previously described. ${ }^{16}$ The percentage of conversion of $\left[{ }^{3} \mathrm{H}\right]$-ATP to $\left[{ }^{3} \mathrm{H}\right]$-cAMP was used to express the adenylyl cyclase activity. The experiments described above were repeated three times for each cell line and means (SD) of the three experiments were presented.

\section{Results}

Exposure to elevated hydrostatic pressure maintained at $50 \mathrm{~mm} \mathrm{Hg}$ for up to 6 hours caused no detectable change in cell viability as assessed by intracellular esterase activity (Table 1). However, the cell morphology was changed with exposure to elevated hydrostatic pressure in all cell lines studied. These changes were characterised by a more rounded shape of the cells that was most prominent in lamina cribrosa astrocytes and trabecular meshwork cells (Fig 1).

To visualise changes in the distribution and organisation of the F-actin cytoskeleton, cells were stained with fluorescent labelled phalloidin, which binds to actin filaments. Human trabecular meshwork cells showed a diffuse and fine filamentous staining in the cytoplasm. When cells were exposed to elevated hydrostatic pressure, redistribution of the actin stress fibres, retraction of processes, and an enhanced polygonal cell shape were observed (Figs 2A and B). Human laminar astrocytes exhibited distinct and prominent stress fibres extending across the cell cytoplasm in control cells. In lamina cribrosa astrocytes exposed to elevated hydrostatic pressure, F-actin staining revealed displacement of the stress fibres to the periphery of the cell cytoplasm in most cells (Figs 2C and D).

Basal adenylyl cyclase activity, as assessed by the percentage of $\left[{ }^{3} \mathrm{H}\right]$-cAMP converted from $\left[{ }^{3} \mathrm{H}\right]-\mathrm{ATP}$, was comparable in all cell lines studied and ranged between $0.2 \%$ and $0.4 \%$. Incubation of the cells under elevated hydrostatic pressure resulted in a time dependent increase in the adenylyl cyclase activity (Fig 3 ). The increase in the basal adenylyl cyclase activity of all cell lines after exposure to elevated hydrostatic pressure for 6 hours is shown in Figure 4. There was no statistical difference among the cell lines in either their control basal adenylyl cyclase activity or the increased cyclase activity following exposure to elevated hydrostatic pressure (multiple comparison test ${ }^{17}, p>0.05$ ). If the cells incubated under elevated hydrostatic pressure for 6 hours were then transferred to normal pressure condition, adenylyl cyclase activity decreased to their initial levels at a rate that was dependent on the time of exposure to elevated hydrostatic pressure. When cells were incubated under elevated hydrostatic pressure for 1 hour, a return to basal levels were observed within 3 hours. However, the recovery period was longer if the cells were incubated under elevated hydrostatic pressure for 6 hours; cells returned to approximately $70 \%$ of their baseline values after 3 hours, with full recovery after 24 hours (data not shown).

In order to assess the capability of cells to maximally activate adenylyl cyclase, individual cell lines were treated with $100 \mu \mathrm{M}$ forskolin in the presence or absence of elevated hydrostatic pressure. Forskolin stimulation of adenylyl cyclase activity was decreased similarly $(\sim 15-$ $20 \%$ ) in all cell lines studied (multiple comparison test, $\mathrm{p}>0.05$ ) following 6 hours' exposure to elevated hydrostatic pressure (Fig $5 \mathrm{~A})$. We also utilised somatostatin to study the ability of cells to inhibit adenylyl cyclase activity following their maximal stimulation with forskolin. Two pertinent findings were noted. Firstly, somatostatin attenuation of forskolin stimulated adenylyl cyclase activity was lower in lamina cribrosa astrocytes compared with other cell lines either in the presence or absence of elevated hydrostatic pressure (multiple comparison test, $\mathrm{p}<0.01$ ). Secondly, although the difference between the response of astrocytes to somatostatin treatment in the presence or absence of elevated hydrostatic pressure did not reach statistically significant levels, astrocytes were the only cells among those studied in which there was increased somatostatin inhibition of forskolin stimulated cyclase activity under elevated hydrostatic pressure (Fig 5B).

\section{Discussion}

Our studies demonstrate that different cell lines derived from ocular tissues exhibit morphological and cellular activity responses following exposure to acute and sustained elevation of 
hydrostatic pressure to $50 \mathrm{~mm} \mathrm{Hg}$ for up to 6 hours. Both phase contrast microscopy in living cells and cytoskeleton examination after phalloidin staining demonstrated that exposure to elevated hydrostatic pressure caused our ocular cells to appear more rounded in shape accompanied by changes in their actin cytoskeleton. In most cells in culture, the actin cytoskeleton is organised as microfilaments, which represent polymerised $\mathrm{F}$-actin. The $\mathrm{F}$-actin microfilament network can be observed at the microscopic level as stress fibres. In accordance with our observations, exposure to physiological or supraphysiological levels of hydrostatic pressure has been reported to cause reorganisation of stress fibres and profound changes in cell shape in a variety of cell types. ${ }^{18-24}$

Although exposure to elevated hydrostatic pressure did not affect cell viability, cellular activity of the intracellular enzyme adenylyl cyclase was notably affected. The basal adenylyl cyclase activity of each cell line significantly increased $(-50-80 \%)$ when incubated under elevated hydrostatic pressure. Maximum adenylyl cyclase activity in the presence of forskolin was calculated as the ratio of stimulated cyclase activity to basal activity. Therefore, decreased forskolin stimulation of adenylyl cyclase activity in all cell lines studied in the presence of elevated hydrostatic pressure is probably related to their increased basal adenylyl cyclase activity.

We observed a distinct difference in the astrocyte response to somatostatin treatment in comparison with the other cell lines studied. Specifically, astrocytes demonstrated the least amount of somatostatin inhibition of forskolin stimulated cyclase activity compared with other cell lines studied. Adenylyl cyclase activity is well known to be modulated by the activity of the stimulatory and inhibitory guanine nucleotide binding proteins, $\mathrm{G}_{\mathrm{s}}$ and $\mathrm{G}_{\mathrm{i}}{ }^{25}$ Since it is often difficult to assess accurately small changes in $G_{i}$ activity by measuring the inhibition of basal adenylyl cyclase activity with drugs such as somatostatin, somatostatin inhibition of forskolin stimulated cyclase is generally used to amplify the $G_{i}$ signal. ${ }^{16}$ Our findings suggest that lamina cribrosa astrocytes behave differently with respect to the efficacy of receptor coupled $G_{i}$ activity under either normal or elevated hydrostatic pressure conditions. This observation is in agreement with previous studies that somatostatin inhibition of stimulated cAMP accumulation provoked by other effectors such as forskolin and isoproterenol is weak in astrocytes. ${ }^{26}$ Although the difference between the response of astrocytes to somatostatin treatment in the presence or absence of elevated hydrostatic pressure did not reach statistically significant levels, astrocytes were the only cells among those studied that demonstrated increased somatostatin inhibition of forskolin stimulated cyclase activity under elevated hydrostatic pressure. Therefore, it appears that astrocytes may behave differently with respect to the regulation of the $G_{s}$ and $G_{i}$ "tone" that governs their adenylyl cyclase activity.

The elevated hydrostatic pressure model used in our experiments in which $50 \mathrm{~mm} \mathrm{Hg}$ pressure was applied for up to 6 hours represents acute pressure elevation with a sustained component. Previous studies demonstrate that functional cell properties may be altered after brief exposure to elevated hydrostatic pressure. For example, cultured astrocytes open stretch activated channels half maximally after extremely brief (that is, seconds) exposure to hydrostatic pressure of $45 \mathrm{~mm} \mathrm{Hg} .{ }^{27}$ Furthermore, hydrostatic pressure $(60-120 \mathrm{~mm} \mathrm{Hg})$ applied to astrocytoma cells for 30-60 minutes induces cell proliferation and DNA synthesis by activation of tyrosine kinase. $^{28}$ Our data suggest that elevated hydrostatic pressure application for several hours can alter intracellular enzyme activity as well as perturb the actin cytoskeleton in ocular cells in vitro. We therefore hypothesise that functional cellular changes in response to brief elevations in external pressure, combined with the recovery that occurs following cessation of elevated pressure in vitro may result in significant changes in the homeostatic functions of several intraocular tissues.

The precise mechanisms of how the cells sense their environment and transduce a physical stimulus such as elevated hydrostatic pressure into a biochemical event, which may eventually lead to morphological and functional cellular changes are unclear. Mechanotransduction is thought to involve a coordinated system of molecules including extracellular matrix receptors, cytoskeletal proteins, and membrane channels. ${ }^{29-31}$ For example, hydrostatic pressure influences the action potential of the plasma membrane and produces depolarisation or hyperpolarisation, depending on the frequency and amplitude of the applied pressure. ${ }^{30}$ The plasma membranes can subsequently respond by increasing synthesis of cAMP, ${ }^{31}$ the cyclic nucleotide that is formed from ATP in reactions catalysed by adenylyl cyclase. Cyclic nucleotides such as cAMP play an important part in the normal metabolism and function of several ocular tissues including ciliary epithelium, trabecular meshwork, retina, and optic nerve. ${ }^{162-36}$ Therefore, increased basal adenylyl cyclase activity in ocular cells exposed to elevated hydrostatic pressure in vitro may reflect a characteristic cell adaptation of ocular cells to elevated intraocular pressure in order to maintain cell survival and function.

The most likely targets for cellular recognition of changes in hydrostatic pressure are the sites where the cell membrane interacts with underlying substrate and with neighbouring cells. The attachment sites of cells to the extracellular matrix and to the neighbouring cells through surface adhesion molecules in turn are connected to the cytoskeleton. One mechanism by which elevated hydrostatic pressure affects the cytoskeleton is thought to be related to regulatory mechanisms such as phosphorylation pathways that control cytoskeletal organisation triggered by activation of adenylyl cyclase in the cell membrane. For example, increased intracellular levels of cAMP and its effector, protein kinase A, can facilitate a reorganisation of the cytoskeleton, yielding 
rounded cells with short processes ${ }^{37}$-in accordance with our findings. The new cytoskeletal organisation observed in the cells exposed to elevated hydrostatic pressure may be a protective effort of these cells since it counteracts the initial membrane changes and potentially strengthens cytoskeletal integrity. ${ }^{31} 38$

In addition, our findings may have broad relevance to the physiological function of the secretory epithelium as they pertain to patients with glaucoma. Recently, it has been proposed that the rate limiting step in active secretion of aqueous humour by the ciliary epithelium is $\mathrm{Cl}$ ion transport via a 4,4'-diisothiocyanostilbene2,2'disulphonate sensitive, cAMP dependent chloride channel..$^{30}$ If elevated hydrostatic pressure, or more importantly, elevated intraocular pressure as occurs in patients with glaucoma, alters adenylyl cyclase activity in the ciliary epithelium as suggested by our findings, it seems quite feasible that cAMP dependent chloride transport, hence aqueous secretion, may be a dynamic process that is directly affected by the pressure level within the eye. This consideration has not yet been addressed in transport studies of the ciliary epithelium, which are typically performed at atmospheric pressure.

In summary, our observations provide evidence in five different cell lines derived from ocular tissues that exposure to sustained levels of hydrostatic pressure increases the level of adenylyl cyclase activity, in addition to reorganisation of the cell cytoskeleton and changes in cell shape. These in vitro observations suggest that key intracellular signalling cascades in ocular cells may be similarly affected by elevated intraocular pressure in vivo. Further studies seem warranted in order to assess other constitutive and altered functional responses of ocular cells to elevated pressure.

This study was supported in part by EY06810, EY12314, EY06416, and EY02687 from the National Institutes of Health, Bethesda, MD, the Glaucoma Research Foundation, San Francisco, CA, USA, and an unrestricted grant to Washington University School of Medicine, Department of Ophthalmology and Visual Sciences from Research to Prevent Blindness Inc, New York, USA.

1 Klein-Nulend J, Van Der Plas A, Semeins CM, et al. Sensitivity of osteocytes to biomechanical stress in vitro. FASEB f 1995; 9:441-5.

2 Yousefian J, Firouzian F, Shanfeld J, et al. A new experimental model for studying the response of periodontal ligament cells to hydrostatic pressure. Am $\mathcal{F}$ Orthod Dent Orthop 1995;108:402-9.

3 Glantschnig H, Varga F, Rumpler M, et al. Prostacyclin $\left(\mathrm{PGI}_{2}\right)$ : a potential mediator of c-fos expression induced by hydrostatic pressure in osteoblastic cells. Eur f Clin Invest hydrostatic pres

4 Acevedo AD, Bowser SS, Gerritsen ME, et al. Morphologi$\mathrm{cal}$ and proliferative responses of endothelial cells to hydrostatic pressure: role of fibroblast growth factor. $\mathcal{F} \mathrm{Cell}$ Physiol 1993;157:603-14.

5 Takahashi K, Kubo T, Kobayashi K, et al. Hydrostatic pressure influences mRNA expression of transforming growth
factor- $\beta 1$ and heat shock protein 70 in chondrocyte-like cell line. f Orthop Res 1997;15:150-8.

6 Yang JL, Neufeld AH, Zorn MB, et al. Collagen type I mRNA levels in cultured human lamina cribrosa cells:
effects of elevated hydrostatic pressure. Exp Eye Res 1993;56:567-74

7 Drance SM, Shulzer M, Douglas GR, et al. Use of discriminant analysis. II. Identification of persons with glaucoma-
tous visual field defects. Arch Ophthalmol 1978;96:57-73.

8 Hart WMN, Yablonski M, Kass MA, et al. Multivariate analysis of the risk of glaucomatous visual field loss. Arch analysis of the risk of glauco
Ophthalmol 1979;97:1455-8.

9 Coca-Prados M, Wax MB. Transformation of human ciliary epithelial cells by simian virus 40: induction of cell proliferation and retention of $\beta_{2}$-adrenergic receptors. Proc Natl Acad Sci USA 1986;83:8754-8.
10 Lee CH, Reisine TD, Wax MB. Alterations of intracellular calcium in human non-pigmented ciliary epithelial cells. Exp Eye Res 1989;48:733-43.

11 Wax MB, Coca-Prados M. Receptor-mediated phosphoinositide hydrolysis in human ocular ciliary epithelial cells. Invest Ophthalmol Vis Sci 1989;30:1675-9.

12 Pang I, Shade DL, Clark AF, et al. Preliminary characterization of a transformed cell strain derived from human trabecular meshwork. Curr Eye Res 1994;13:51-63.

13 Seigel GM. Establishment of an E1A-immortalized retinal cell culture in vitro. Cell Dev Biol 1996;32:66-8.

14 Kobayashi S, Vidal I, Pena JDO, et al. Expression of neural cell adhesion molecule (NCAM) characterizes a subpopulation of type 1 astrocytes in human optic nerve head. Glia 1997;20:262-73.

15 Haugland RP, Larison KD. Fluorescent dyes for assessing vital cell functions. In: Handbook of fluorescent probes and research chemicals. 5th ed. Eugene, Oregon: Molecular research chemicals. 5th
Probes, 1992-4:172-80.

16 Wax MB, Barret DA. Regulation of adenylyl cyclase in rabbit iris ciliary body. Curr Eye Res 1993;12:507-20.

17 Kirk RE. Multiple comparison test. In: Experimental design: procedures for the behavioral sciences. Belmont, CA: Brooks and Cole, 1968:69-81.

8 Meyer-Franke A, Kaplan MR, Pfrieger FW, et al. Characterization of the signaling interactions that promote the survival and growth of developing retinal ganglion cells in culture. Neuron 1995;15:805-19.

19 Shi J, Marinowich A, Barres BA. Purification and characterization of adult oligodendrocyte precursor cells from the rat optic nerve. $\mathcal{F}$ Neurosci 1998;18:4627-36.

20 Haskin C, Cameron I. Physiological levels of hydrostatic pressure alter morphology andorganization of cytoskeletal and adhesion molecules in MG-63 osteosarcoma cells. Biochem Cell Biol 1993;71:27-35.

21 Haskin CL, Athanasiu KA, Klebe R, et al. A heat-shock response with cytoskeletal disruption occurs following
hydrostatic pressure in MG-63 osteosarcoma cells. Biochem Cell Biol 1993;71: 361-71.

22 Parkkinen JJ, Lammi MJ, Inkinen R, et al. Influence of short term hydrostatic pressure on organization of stress fibers in cultured chondrocytes. F Orthop Res 1995;13:495-502.

23 Smith RL, Rusk SF, Ellison BE, et al. In vitro stimulation of articular chondrocyte mRNA and extracellular matrix synthesis by hydrostatic pressure. F Orthop Res 1996;14:53-60.

24 Rubin J, Biskobing D, Fan X, et al. Pressure regulates osteoclast formation

25 Lefkowitz RJ, Hoffman BB, Taylor P. Neurotransmission. The autonomic and somatic motor nervous systems. In: Hardman JG, Limbird LE, Molinoff PB, et al, eds. Goodman $\mathcal{E}$ Gilman's the pharmocological basis of therapeutics. 9th ed. New York, St Louis, San Francisco: McGrawHill, 1996:105-39.

26 Colas B, Arilla E, Prieto JP. Somatostatin binding to a fresh rat astrocyte-enriched suspension. Neuropeptides 1992;23: $1-7$.

27 Islas L, Pasantes-Morales H, Sanchez JA. Characterization of stretch activated ion channels in cultured astrocytes. Glia 1993;8:87-96.

28 Oishi Y, Uezono Y, Yanagihara N, et al. Transmural compression-induced proliferation and DNA synthesis through activation of a tyrosine kinase pathway in astrocytoma RCR-1 cells. Brain Res 1998;781:159-66.

29 Bowman CL, Ding J-P, Sachs F, et al. Mechanotransducing ion channels in astrocytes. Brain Res 1992;584:272-86.

30 Wright MO, Stockwell RA, Nuki G. Response of plasma membrane to applied hydrostatic pressure in chondrocytes membrane to applied hydrostatic pressure in chondro
and fibroblasts. Connect Tissue Res 1992;28:49-70.

31 Banes AJ, Tsuzaki M, Yamamoto J, et al. Mechanoreception at the cellular level: the detection, interpretation, and diversity of responses to mechanical signals. Biochem Cell Biol 1995;73:349-65.

32 Glogauer M, Arora P, Yao G, et al. Calcium ions and tyrosine phosphorylation interacts coordinately with actin to regulate cytoprotective responses to stretching. $\mathcal{F} \mathrm{Cell} \mathrm{Sci}$ 1997;110:11-2.

33 Veldhuijzen JP, Bourret LA, Rodan G. In vitro studies of the effect of intermittent compressive forces on cartilage cell proliferation. F Cell Physiol 1979;98:299-306.

34 Kaufman PL. Adenosine 3', 5'-cyclic-monophosphate and outflow facility in monkey eyes with intact and retrodisplaced ciliary muscle. Exp Eye Res 1987;44:415-23.

35 Crook RB, Polansky JR. Stimulation of $\mathrm{Na}+, \mathrm{K}+, \mathrm{Cl}-$ cotransport by forskolin-activated adenylylate cyclase in cotransport by forskolin-activated adenylylate cyclase in Ophthalmol Vis Sci 1994;35:3374-83.

36 Civan MM, Coca-Prados M, Peterson-Yantorno K. Pathways signaling the regulatory volume decrease of cultured non-pigmented ciliary epithelial cells. Invest Ophthalmol Vis Sci 1994;35:2876-86.

37 Crenshaw HC, Allen JA, Skeen V, et al. Hydrostatic pressure has different effects on the assembly of tubulin, actin, myosin II, vinculin, talin, vimentin, and cytokeratin in mammalian tissue cells. Exp Cell Res 1996; 227:285-97.

38 Han J, Rubin CS. Regulation of cytoskeleton organization and paxillin dephosphorylation by cAMP. F Biol Chem 1996; 271:29211-5.

39 Chen $\mathrm{S}$, Inoue $\mathrm{R}$, Inomata $\mathrm{H}$, et al. Role of cyclic AMP-induced $\mathrm{Cl}$ conductance in aqueous humour formation by the $\operatorname{dog}$ ciliary epithelium. $B r \quad \mathcal{f}$ Pharmacol 1994;112:1137-45.

40 Jacob TJ, Civan MM. Role of ion channels in aqueous humor formation. Am f Physiol 1996;271:C703-20. 